\title{
Application of Risk Estimation of Noise-induced Hearing Loss Method in Evaluations of Oc- cupational Disease Hazards in Construction Projects in China*
}

\author{
Minyan Li, Deyin Huang ${ }^{\dagger}$, Qian Zhang \\ Institute of Occupational Health, Tianjin Bohai Chemical Industry Group Co. Ltd, Tianjin 300051,China
}

Mao Liu

Centre for Urban Public Safety Research, Nankai University, Tianjin 300071,China

Received 10 September 2016

Accepted 20 April 2016

\begin{abstract}
To protect the workers exposed to industrial noise, prevent and control the occurrence of noise-induced hearing loss, and reduce the incidence of occupational noise-induced deafness, a method and its application example were presented to assess the risk of noise-induced hearing loss. Based on the data collected by occupational hygienic investigations and measurements, the consequences and probabilities of noise-induced hearing loss could be predicted by using the ISO 1999:2013(E) risk model when the appropriate frequency combinations of interest and fences have been chosen according to the need, and then the corresponding management measures should be taken. It shows that this method could be widely used in evaluations of occupational disease hazards in construction projects in China. It will provide the technical basis in aspect of hearing protection for enterprises, assessment organizations and administration to improve the occupational health management continuously, to give reasonable advices for enterprises to protect the workers' hearing, and to supervise and inspect the industrial occupational health situations, respectively.
\end{abstract}

Keywords: Hearing loss, Noise, Occupational disease, Risk assessment, ISO 1999

\section{Introduction}

In China and abroad, guidelines and criterion have been drafted to evaluate the health risk of people exposed to the toxic chemical substances, while in respect to the health risk assessment of noise, a set of systemic acoustics criterion have been set by ISO/TC 43, acoustics committee. A noise-induced health risk estimation method is introduced in ISO 1999 in detail, and the health effects in this model only refers to hearing loss.

ISO (the International Organization for Standardization) published the first edition of ISO 1999, i.e. ISO 1999:1975(E) "Acoustics - Assessment of occupational noise exposure for hearing conservation purposes", which gave the method to measure the noise and listed the risk of hearing impairment for conversation speech frequencies $(500 \mathrm{~Hz} 、 1000 \mathrm{~Hz} 、 2000 \mathrm{~Hz})$ when people exposed to different noise levels for different durations. After that, ISO 1999: 1990(E) was published to cancel and replace the first edition, and in China, the first standard to assess the noise-induced hearing loss GB/T 14366-93 "Acoustics- Determination of occupational noise exposure and estimation of noise-induced hearing impairment" (MOD ISO 1999:1990(E)) was published. Compared to the 1975 edition, hearing loss of different frequencies $(500 \mathrm{~Hz} 、 1000 \mathrm{~Hz} 、 2000 \mathrm{~Hz} 、 3000 \mathrm{~Hz} 、 4000$ $\mathrm{Hz} 、 6000 \mathrm{~Hz}$ ) of both genders exposed to different noise levels for different durations and method to calculate the

\footnotetext{
* This study was supported by Municipal Key Science and Technology Support Project of Tianjin (No. 13ZCZDSY02300).

Corresponding Author: huang_deyin@126.com
} 
risk of noise-induced impairment was added. Recently, the latest edition ISO 1999: 2013(E) “Acoustics- Estimation of noise-induced hearing loss" was published to cancel and replace the second one, while GB/T 14366-93 has not been updated yet. Data of database B are added in the third edition compared to the second one with some details revised. An approval AQ standard "Risk Management Guidelines for Noise Occupational Disease Hazard" drafted by our team introducing the latest ISO model to estimate noise-induced hearing loss will be published very soon.

Based on the ISO 1999:2013(E), method to estimate the risk of noise-induced hearing loss is introduced and applied in the noise occupational disease hazard assessment. The frequency combinations and fences matching the present state of Chinese assessment of occupational hazard are selected to estimate the noise-induced hearing loss to guide the employing unit to take corresponding management measures according to the different risk levels.

\section{Method}

\subsection{Investigation on the Noise Occupational Exposure Situation}

The investigation on the noise occupational exposure situation includes production process, the fixed number of staff members of each workshop post and their tasks, the exposure situation of each post, the selection and use of hearing protectors, the draft and implement situation of hearing conservation program and occupational epidemiology data collection of similar enterprises in China, etc. According to the investigation results, the noise sources and workers affected could be identified to be used to analysis the occupational exposure characteristics.

\subsection{Evaluation of the Occupational Noise Ex- posure}

The instruments used, the places to measure noise and the method to measure and calculate the sound levels all should be according to GBZ/T 189.8. A-weighted noise exposure level normalized to a nominal $8 \mathrm{~h}$ working day or nominal week of 5 eight-hour working days could be used to determine whether workers need to wear hearing protectors or not.

When the sound levels of the workplaces could not be measured, the occupational noise exposure levels could be forecast according to the measure data of similar enterprises in China or the past measure data of the workplaces of the employing unit itself.

\subsection{Risk Assessment of Noise-induced Hearing Loss}

The potential risk of occupational noise-induced hearing loss could be quantitatively expressed by the noise-induced permanent threshold shift (NIPTS) and the percentages of a population whose hearing threshold level associated with age and noise (HTLAN) and hearing threshold level associated with age (HTLA) exceed the fence. To assess the risk of hearing loss and to estimate the hearing loss of hearing threshold level associated with age and noise and noise-induced permanent threshold shift is the manner to evaluate the affect that the noise induced in the occupational population. After selecting the appropriate frequency combinations and fences, percentages in the population whose HTLAN and HTLA of the selected frequency combinations which exceed the fences could be calculated, so that the NIPTS and the percentages of a population whose HTLAN and HTLA exceeds the fence could be estimate.

\subsubsection{Select the appropriate frequency combina- tions and fences}

The hearing threshold level of the chosen frequency combinations could be used to evaluate the noise-induced hearing loss, so the first step is to select the frequencies of interest and the appropriate fence according to the objective of the noise occupational disease hazard risk assessment.

(1) Choose the average hearing threshold level of high frequencies $(3000 \mathrm{~Hz} 、 4000 \mathrm{~Hz}$ and $6000 \mathrm{~Hz})$ of any ear and the fence as $10 \mathrm{~dB}$, according to the " high-frequency standard threshold shift (HSTS)" defined in the "Hearing Protection Specification for Employee in Industrial Enterprises" published by Ministry of Health of the People's Republic of China in 1999. The related noise occupational disease hazard evaluation results will be used to guide managers to take appropriate measures. The specification provides that the enterprises should take measures to protect the hearing of those who have HSTS to prevent a further hearing loss. 
(2) Choose the average hearing threshold level of high frequencies $(3000 \mathrm{~Hz} 、 4000 \mathrm{~Hz}$ and $6000 \mathrm{~Hz})$ of both ears and the fence as $40 \mathrm{~dB}$, according to the precondition to be diagnosed as occupational noise deaf patients in accordance with the GBZ 49-2014. The related noise occupational disease hazard evaluation results will be used to remind the managers to take appropriate measures before someone has been diagnosed as an occupational noise deaf patient.

(3) Choose the weighted average hearing threshold level of speech frequencies $(500 \mathrm{~Hz}, 1000 \mathrm{~Hz}$ and $2000 \mathrm{~Hz})$ and high frequency $(4000 \mathrm{~Hz})$ of better ear, i.e. $1 / 3 \times[$ HL500 Hz+HL1000 Hz+HL2000 $\mathrm{Hz}] \times 0.9+\mathrm{HL} 4000 \mathrm{~Hz} \times 0.1$, and the fence as $25 \mathrm{~dB}$, according to the diagnose results of the occupational noise deafness level according to the GBZ 49-2014. The related noise occupational disease hazard evaluation results will be used to warn the managers that occupational noise deafness cases will occur if no measures have been taken.

\subsubsection{Hearing threshold level associated with age and noise (HTLAN)}

The hearing threshold level, in decibels, associated with age and noise (HTLAN), H', of a noise-exposed population is calculated, for the purposes of this ISO model, by using Formula (1):

$$
H^{\prime}=H+N-\frac{H \times N}{120}
$$

where

$\mathrm{H}^{\prime}$ is the hearing threshold level, expressed in decibels, associated with age and noise (HTLAN);

$\mathrm{H}$ is the hearing threshold level, expressed in decibels, associated with age (HTLA);

$\mathrm{N}$ is the actual or potential noise-induced permanent threshold shift (NIPTS), expressed in decibels.

This formula is applicable only to corresponding percentage values of $\mathrm{H}^{\prime}$, $\mathrm{H}$, and $\mathrm{N}$.

Note that the relationship expressed in Formula (1) is an approximation to the biological events and is considered accurate enough for the purposes of this ISO model. The term $(\mathrm{H} \times \mathrm{N}) / 120$ starts to significantly modify the result only when $\mathrm{H}+\mathrm{N}$ is more than approximately $40 \mathrm{~dB}$.

\subsubsection{Databases for hearing threshold levels as} sociated with age (HTLA)

\subsubsection{Choice of database}

The hearing of a non-noise-exposed population as a function of age depends on the degree to which other factors besides aging are inadvertently included; diseases, history of ototoxic drugs, and unknown noise exposure of occupational or non-occupational origin may modify the HTLA. Different approaches to screening such data have been used and the selection of the most appropriate database depends on the purpose of the application. Two databases (databases A and B) to be used for HTLA should be according to the specification in ISO 1999:2013(E).

\subsubsection{Database A}

Database A derives from otologically normal persons. The statistical distributions of the thresholds of such highly screened populations have been standardized in GB/T 7582 separately for male and female populations.

There are two ways to acquired database A: (1) calculating database A by formulae specified in ISO 1999:2013(E), and (2) the look-up table method by using the tables of database A provided in the ISO model.

The formulae applicable for the hearing threshold level, $\mathrm{H}$, as a function of age, $\mathrm{Y}$ (years), for the various ranges of the percentage, $\mathrm{Q}$, could be expressed as:

for $\mathrm{Q}=50 \%$ :

$$
H_{\mathrm{md}, \mathrm{Y}}=a(Y-18)^{2}+H_{\mathrm{md}, 18}
$$

for $5 \% \leqslant Q<50 \%$ :

$$
H_{Q}=H_{\mathrm{md}, \mathrm{Y}}+k s_{u}
$$

for $50 \%<\mathrm{Q} \leqslant 95 \%$ :

$$
H_{Q}=H_{\mathrm{md}, \mathrm{Y}}-k s_{l}
$$

where,

$s_{\mathrm{u}}$ is the standard deviation of the upper half of the distribution; 
$s_{1}$ is the standard deviation of the lower half of the distribution;

$H_{\mathrm{md}, 18}$ is the median value of the hearing threshold of otologically normal persons of the same sex aged 18 years, which for practical purposes is taken as zero. Hence, $H_{Q}$ has been termed the hearing threshold level associated with age.

Here, the values for the multiplier $k$ corresponding to the normal (Gaussian) distribution, the values for the coefficient could be looked up in the tables of ISO 1999: 2013(E), and the parameters $s_{\mathrm{u}}$ and $s_{1}$ could be calculated by formulae given in this ISO standard.

\subsubsection{Database B}

Three examples of database B are presented in ISO 1999: 2013(E) for an unscreened population (males and females). These examples are compiled from representative data from three industrialized countries: Sweden (B.2), Norway (B.3), and the United States (B.4). B.2 and B.3 represent populations who have not been exposed to occupational noise, while subjects with occupational noise exposure are included in B.4.

\subsubsection{Noise-induced permanent threshold shift}

\subsubsection{Calculation of N50}

The median potential NIPTS values to be used are functions of audiometric frequency, the exposure duration, the ratio $t / t 0$, and the noise exposure level normalized to a nominal $8 \mathrm{~h}$ working day, $L_{\mathrm{EX}, 8 \mathrm{~h}}$, and 5 days per week, averaged over the exposure duration $t$.

For exposure durations between 10 years and 40 years, the median potential NIPTS values, $N_{50}$, in decibels, are given for both genders by Formula (5):

$$
N_{50}=\left[u+v \lg \left(t / t_{0}\right)\right]\left(L_{\mathrm{EX}, 8 \mathrm{~h}}-L_{0}\right)^{2}
$$

where

$L_{\mathrm{EX}, 8 \mathrm{~h}}$ is the noise exposure level normalized to a nominal $8 \mathrm{~h}$ working day, expressed in decibels;

$L_{0}$ is the sound pressure level, defined as a function of frequency, expressed in decibels, below which the effect on hearing is negligible;

$t$ is the exposure duration, expressed in years;

$t_{0}$ is 1 year;

$u, v$ and $L_{0}$ are given as a function of frequency in Table 1 in ISO 1999:2013(E).
For exposure durations less than 10 years, $N$ shall be extrapolated from the value of $N_{50}$ for 10 years using Formula (6):

$$
N_{50, t<10}=\frac{\lg (t+1)}{\lg (11)} N_{50, t=10}
$$

Formula (6) is valid for exposure durations between 1 year and 10 years.

\subsubsection{Statistical distribution of noise-induced permanent threshold shift, $N$}

For the purposes of ISO 1999:2013(E), the statistical distribution of $N$ is approximated by two different halves of two normal (Gaussian) distributions. The upper half, for the percentage with hearing worse than the median, is characterized by the parameter $d_{\mathrm{u}}$; the lower half has a smaller dispersion characterized by the parameter percentage $d_{1}$. For a percentage of, $Q$, of the population such that $5 \% \leq Q<50 \%$, the NIPTS is given by Formula (7):

$$
N_{Q}=N_{50}+k d_{u}
$$

For a percentage of, $Q$, of the population such that $50 \%<Q \leq 95 \%$, the NIPTS is given by Formula (8):

$$
N_{Q}=N_{50}-k d_{l}
$$

$d_{\mathrm{u}}$ and $d_{1}$ shall be calculated in accordance with corresponding specification in ISO 1999:2013(E).

Besides, the three particular values $N_{10}, N_{50}, N_{90}$ can also be looked up from the table provided in the ISO model.

\section{Noise-induced Risk Management}

Based on the assessment results of risk of hearing loss due to noise exposure, the key of risk management is to reduce $N$. For the workers who have HSTS, managers should take measures to prevent a further hearing loss; for those who meet the precondition to be diagnosed as occupational noise deaf patients, they should be considered to be diagnosed and classified according to their situation; and for those already have been diagnosed as occupational noise deaf patients, they should be transferred off the noise workplaces. 


\section{Application Example Analysis}

There are 36 winding machines in Winding Workshop of Polymers Section of Cell 2 Department in the battery assembly enterprise evaluated, the occupational hazard of which is identified and analyzed in a status quo assessment. 104 workers in this workshop exposed to noise when working in this area.

\subsection{Objects}

\subsubsection{Principles to choose objects}

The population selected in the application example analysis should meet the requirements as follows: have
(1) no prior employment (with a different employer) in a high noise environment; (2) no ear disease or history of ear disease; (3) no family history of hearing loss; (4) no history of diabetes; (5) never use ototoxic drugs; (6) no non-occupational noise exposure; (7) no other hearing loss risk factors.

\subsubsection{Objects to assess}

Choose workers exposed to noise of this workshop as objects whose risk of noise-induced hearing loss will be assessed. They are mostly male between 20 and 30 years old. The fixed number of staff members of the workshop post and their tasks, and the exposure situation of each post are given in Table 1.

Table 1. The fixed number of staff members of the workshop post and their tasks, and the exposure situation of each post

\begin{tabular}{|c|c|c|c|c|}
\hline Posts & $\begin{array}{c}\text { Number of staff } \\
\text { members per } \\
\text { shift }\end{array}$ & Shifts & $\begin{array}{c}\text { Total number of } \\
\text { staff members }\end{array}$ & Tasks and operate time \\
\hline Operators A & 10 & $\begin{array}{l}\text { Three shifts with three changing } \\
\text { from Monday to Thursday and three } \\
\text { shifts with two changing from Friday } \\
\text { to Sunday }\end{array}$ & 30 & $\begin{array}{l}\text { They operate on the No.7, No.8, No.11, and } \\
\text { No.13 winding machines and work for } 7 \mathrm{~h} \text { per } \\
\text { shift from Monday to Thursday and for } 10 \mathrm{~h} \text { per } \\
\text { shift from Friday to Sunday. }\end{array}$ \\
\hline Operators B & 9 & Four shifts with three changing & 36 & $\begin{array}{l}\text { They operate on the No.9, No.10, and No. } 12 \\
\text { winding machines and work for } 7 \mathrm{~h} \text { per shift for } 5 \\
\text { days per week. }\end{array}$ \\
\hline Monitors A & 2 & $\begin{array}{l}\text { Three shifts with three changing } \\
\text { from Monday to Thursday and three } \\
\text { shifts with two changing from Friday } \\
\text { to Sunday }\end{array}$ & 6 & $\begin{array}{l}\text { They check on the No.7, No.8, No.11, and No. } 13 \\
\text { winding machines and work for } 7 \mathrm{~h} \text { per shift from } \\
\text { Monday to Thursday and for } 10 \mathrm{~h} \text { per shift from } \\
\text { Friday to Sunday. }\end{array}$ \\
\hline Monitors B & 2 & Four shifts with three changing & 8 & $\begin{array}{l}\text { They check on the No.9, No. } 10 \text {, and No. } 12 \\
\text { winding machines and work for } 7 \mathrm{~h} \text { per shift for } 5 \\
\text { days per week. }\end{array}$ \\
\hline $\begin{array}{l}\text { Precision } \\
\text { monitors A }\end{array}$ & 2 & $\begin{array}{l}\text { Three shifts with three changing } \\
\text { from Monday to Thursday and three } \\
\text { shifts with two changing from Friday } \\
\text { to Sunday }\end{array}$ & 6 & $\begin{array}{l}\text { They check on the No.7, No. } 8 \text {, No.11, and No. } 13 \\
\text { lines and work for } 7 \mathrm{~h} \text { per shift from Monday to } \\
\text { Thursday and for } 10 \mathrm{~h} \text { per shift from Friday to } \\
\text { Sunday. }\end{array}$ \\
\hline $\begin{array}{l}\text { Precision } \\
\text { monitors B }\end{array}$ & 2 & Four shifts with three changing & 8 & $\begin{array}{l}\text { They check on the No.9, No.10, and No.12 lines } \\
\text { and work for } 7 \mathrm{~h} \text { per shift for } 5 \text { days per week. }\end{array}$ \\
\hline
\end{tabular}

\subsection{Method}

\subsubsection{Noise occupational exposure evaluation}

The noise exposure levels of workers in this workshop are given in Table 2 .

Based on the measurement results, the calculated $L_{\mathrm{EX}, \mathrm{W}}$ of workers in this workshop is between $85.2 \mathrm{~dB}$ and $88.0 \mathrm{~dB}$, with the average of $86.9 \mathrm{~dB}$.

\subsubsection{Risk of hearing loss due to noise}

Assume that the male workers exposed to the industrial noises of this workshop without any personnel hearing protectors from 20 years old, and the noise exposure level $L_{\mathrm{EX}, \mathrm{W}}=86.9 \mathrm{~dB}$. Predict the HSTS and occupational noise deafness risks of population when they are $30,40,50$ or 60 years old.

A Microsoft ${ }^{\circledR}$ Excel worksheet was compiled based on the method given before and the information above was input. 
Table 2. A-weighted noise exposure level normalized to a nominal week of 5 eight-hour working days (LEX,W) of workers of Winding Workshop of Polymers Section of Cell 2 Department.

\begin{tabular}{|c|c|c|}
\hline Workshop & Posts & $L_{\mathrm{EX}, \mathrm{W}}(\mathrm{dB})$ \\
\hline \multirow{27}{*}{$\begin{array}{l}\text { Winding } \\
\text { Work- } \\
\text { shop of } \\
\text { Poly- } \\
\text { mers } \\
\text { Section }\end{array}$} & Monitor of Line 8 & 87.4 \\
\hline & Monitor of Line 12 & 86.7 \\
\hline & Precision monitor of Line 9 and Line 10 & 85.6 \\
\hline & Precision monitor of Line 7 and Line 11 & 87.4 \\
\hline & Precision monitor of Line 8 & 87.6 \\
\hline & Precision monitor of Line 12 & 86.7 \\
\hline & Precision monitor of Line 9 and Line 10 & 86.0 \\
\hline & Precision monitor of Line 7 and Line 11 & 87.6 \\
\hline & Operator A of Line 7 and Line 11 & 87.6 \\
\hline & Operator B of Line 7 and Line 11 & 87.6 \\
\hline & Operator D of Line 7 and Line 11 & 87.9 \\
\hline & Operator D of Line 7 and Line 11 & 86.9 \\
\hline & Operator E of Line 7 and Line 11 & 87.8 \\
\hline & Operator A of Line 9 and Line 10 & 85.8 \\
\hline & Operator B of Line 9 and Line 10 & 85.6 \\
\hline & Operator D of Line 9 and Line 10 & 85.2 \\
\hline & Operator D of Line 9 and Line 10 & 86.3 \\
\hline & Operator E of Line 9 and Line 10 & 85.7 \\
\hline & Operator of Line 13 & 87.6 \\
\hline & Operator A of Line 8 & 87.2 \\
\hline & Operator B of Line 8 & 87.4 \\
\hline & Operator $\mathrm{C}$ of Line 8 & 87.4 \\
\hline & Operator D of Line 8 & 88.0 \\
\hline & Operator A of Line 12 & 86.7 \\
\hline & Operator B of Line 12 & 85.9 \\
\hline & Operator $\mathrm{C}$ of Line 12 & 86.6 \\
\hline & Operator D of Line 12 & 86.9 \\
\hline
\end{tabular}

\subsection{Results}

Choose database A to calculate the hearing threshold level associated with age, and use the compiled Excel worksheet to predict the HSTS and occupational noise deafness risk for these male workers if they do not wear any hearing protectors.

\section{(1) Risk of HSTS}

The predicted risks of HSTS are given in Table 3 and the risk assessment results are expressed in Fig. 1.

The results show that $H$ and $H^{\prime}$ both increase with the duration and $N$ presents an increasing trend on the condition of fixed initial exposure age and exposure noise level. However, the risk of HSTS due to noise decreases after a number of years of exposure. This is an inherent disadvantage of the concept. It should not be interpreted as if the harmful effects of noise cease to exist. The explanation is that people who have crossed the fence because of age-related threshold shifts are no longer eligible for a risk of hearing loss due to noise

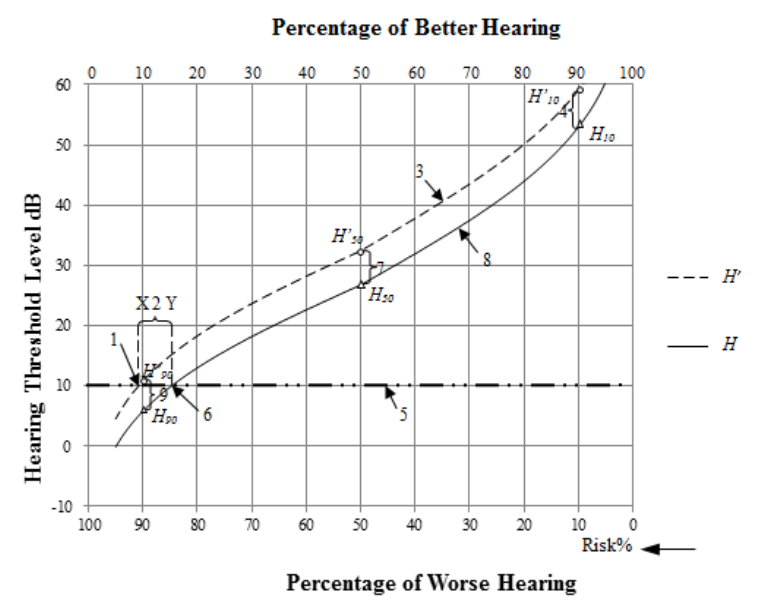

Fig.1. Assessment results of HSTS risk for male workers of the workshop at the age of 60 .

In Fig 1, we have:

(1) Risk of hearing loss due to age and noise exposure, $90.8 \% \%$ (point X);

(2) Risk of hearing loss due to noise exposure, $6.1 \% \%$ (difference between point $\mathrm{X}$ and point $\mathrm{Y}$ );

Table 3. Predicted risk of HSTS for the male workers in this workshop.

\begin{tabular}{|c|c|c|c|c|c|c|c|c|c|c|c|c|c|}
\hline $\begin{array}{c}\text { Age } \\
\text { (years) }\end{array}$ & $\begin{array}{c}\text { Duration } \\
\text { (years) }\end{array}$ & $\begin{array}{l}H^{\prime}{ }_{10} \\
\text { (dB) }\end{array}$ & $\begin{array}{l}H^{\prime}{ }_{50} \\
(\mathrm{~dB})\end{array}$ & $\begin{array}{l}H_{90}^{\prime} \\
(\mathrm{dB})\end{array}$ & $\begin{array}{l}H_{10} \\
(\mathrm{~dB})\end{array}$ & $\begin{array}{l}H_{50} \\
\text { (dB) }\end{array}$ & $\begin{array}{l}H_{90} \\
(\mathrm{~dB})\end{array}$ & $\begin{array}{l}N_{10} \\
(\mathrm{~dB})\end{array}$ & $\begin{array}{l}N_{50} \\
(\mathrm{~dB})\end{array}$ & $\begin{array}{l}N_{90} \\
(\mathbf{d B})\end{array}$ & \begin{tabular}{|l|} 
Risk of \\
hearing \\
loss due \\
to age and \\
noise \\
exposure \\
$(\%)$ \\
$\%)$
\end{tabular} & $\begin{array}{l}\text { Non-noise- } \\
\text { exposed } \\
\text { population } \\
\text { risk of } \\
\text { hearing } \\
\text { loss due to } \\
\text { age (\%) }\end{array}$ & $\begin{array}{l}\text { Risk of } \\
\text { hearing } \\
\text { loss due to } \\
\text { age and } \\
\text { noise } \\
\text { exposure } \\
(\%)\end{array}$ \\
\hline 30 & 10 & 21.5 & 7.5 & -4.5 & 14.4 & 2.2 & -7.6 & 7.1 & 5.3 & 3.0 & 40.9 & 20.5 & 20.4 \\
\hline 40 & 20 & 30.2 & 13.3 & -0.5 & 22.5 & 7.3 & -4.8 & 7.7 & 5.9 & 4.2 & 62.1 & 41.1 & 21.0 \\
\hline 50 & 30 & 42.6 & 21.5 & 4.5 & 35.3 & 15.5 & -0.3 & 7.3 & 6.0 & 4.8 & 80.8 & 67.3 & 13.5 \\
\hline 55 & 35 & 50.3 & 26.6 & 7.5 & 43.5 & 20.8 & 2.5 & 6.8 & 5.9 & 4.9 & 86.8 & 77.6 & 9.2 \\
\hline 60 & 40 & 59.1 & 32.4 & 10.8 & 52.9 & 26.8 & 5.8 & 6.1 & 5.7 & 5.0 & 90.8 & 84.7 & 6.1 \\
\hline
\end{tabular}


(3) HTLA of noise-exposed population;

(4) NIPTS, $10 \%$;

(5) Assumed fence, $10 \mathrm{~dB}$;

6) Non-noise- exposed population risk of hearing loss due to age, $84.7 \% \%$ (point Y);

(7) NIPTS, $50 \%$;

(8) HTLA of non-noise-exposed population;

(9) NIPTS, $90 \%$.

(2) Risk of occupational noise deafness

The predicted risks of occupational noise deafness are given in Table 4 and the risk assessment results are expressed in Fig. 2.
(4) NIPTS, $10 \%$;

(5) Assumed fence, $10 \mathrm{~dB}$;

6) Non-noise- exposed population risk of hearing loss due to age, $10.1 \% \%$ (point Y);

(7) NIPTS, $50 \%$;

(8) HTLA of non-noise-exposed population;

(9) NIPTS, $90 \%$.

The results show that $H$ and $H$ ' both increase with the duration and $N$ presents an increasing trend on the condition of fixed initial exposure age and exposure noise level.

Tails of the statistical distributions for $0 \%<\mathrm{Q}<5 \%$

Table 4. Predicted risk of occupational noise deafness for the male workers in this workshop

\begin{tabular}{|c|c|c|c|c|c|c|c|c|c|c|c|c|c|}
\hline $\begin{array}{l}\text { Age } \\
\text { (years) }\end{array}$ & $\begin{array}{l}\text { Duration } \\
\text { (years) }\end{array}$ & $\begin{array}{l}H_{10}^{\prime} \\
(\mathrm{dB})\end{array}$ & $\begin{array}{l}H^{\prime}{ }_{50} \\
\text { (dB) }\end{array}$ & $\begin{array}{l}H^{\prime}{ }_{90} \\
\text { (dB) }\end{array}$ & $\begin{array}{l}H_{10} \\
\text { (dB) }\end{array}$ & $\begin{array}{l}H_{50} \\
\text { (dB) }\end{array}$ & $\begin{array}{l}H_{90} \\
(\mathrm{~dB})\end{array}$ & $\begin{array}{l}N_{10} \\
(\mathrm{~dB})\end{array}$ & $\begin{array}{l}N_{50} \\
\text { (dB) }\end{array}$ & $\begin{array}{l}N_{90} \\
\text { (dB) }\end{array}$ & $\begin{array}{l}\text { Risk of } \\
\text { hearing } \\
\text { loss due to } \\
\text { age and } \\
\text { noise } \\
\text { exposure } \\
(\%)\end{array}$ & $\begin{array}{l}\text { Non-noise- } \\
\text { exposed } \\
\text { population } \\
\text { risk of } \\
\text { hearing loss } \\
\text { due to age } \\
(\%)\end{array}$ & $\begin{array}{l}\text { Risk of } \\
\text { hearing } \\
\text { loss due to } \\
\text { age and } \\
\text { noise } \\
\text { exposure } \\
(\%)\end{array}$ \\
\hline 30 & 10 & 11.5 & 1.8 & -5.9 & 9.9 & 0.9 & -6.4 & 1.6 & 1.0 & 0.5 & $0-5.0$ & $0-5.0$ & $0-5.0$ \\
\hline 40 & 20 & 15.0 & 4.2 & -4.4 & 13.1 & 2.9 & -5.3 & 1.9 & 1.3 & 0.9 & $0-5.0$ & $0-5.0$ & $0-5.0$ \\
\hline 50 & 30 & 20.0 & 7.6 & -2.4 & 18.1 & 6.1 & -3.5 & 1.9 & 1.5 & 1.1 & $0-5.0$ & $0-5.0$ & $0-5.0$ \\
\hline 55 & 35 & 23.2 & 9.6 & -1.2 & 21.3 & 8.1 & -2.4 & 1.8 & 1.5 & 1.2 & 7.3 & 5.1 & 2.2 \\
\hline 60 & 40 & 26.8 & 12.0 & 0.1 & 25.0 & 10.5 & -1.1 & 1.7 & 1.5 & 1.2 & 13.0 & 10.1 & 2.9 \\
\hline
\end{tabular}

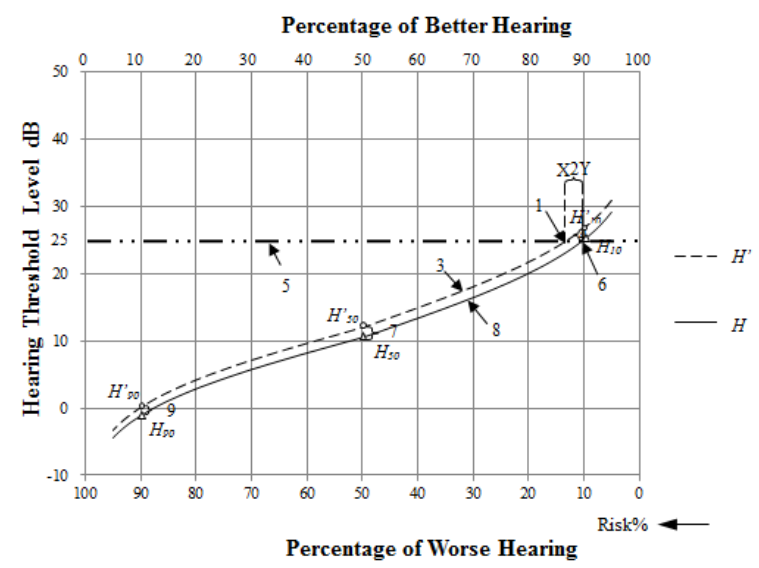

Fig.2. Assessment results of risk of occupational noise deafness for male workers of the workshop at the age of 60 .

In Fig 2, we have:

(1) Risk of hearing loss due to age and noise exposure, $13.0 \% \%$ (point X);

(2) Risk of hearing loss due to noise exposure, $2.9 \% \%$ (difference between point $\mathrm{X}$ and point $\mathrm{Y}$ );

(3) HTLA of noise-exposed population; and for $95 \%<\mathrm{Q}<100 \%$ are unreliable and should not be estimated since few experimental data exist to validate these ranges.

(3) Hearing loss of different frequencies

It shows that the hearing threshold level of $4000 \mathrm{~Hz}$ is the maximum of $H^{\prime}{ }_{50}$ and $N_{50}$, the curve of audiogram shows a $\mathrm{V}$ shape, and $H^{\prime}{ }_{50}$ and $N_{50}$ of every frequency both increase with the duration on the condition of fixed initial exposure age and exposure noise level (Table 5, Fig. 3 and Table 6, Fig. 4 ).

Table 5. Predicted results of H'50 of each frequency for the male workers of the workshop

\begin{tabular}{|l|c|c|c|c|c|c|c|}
\hline \multirow{2}{*}{$\begin{array}{c}\text { Age } \\
\text { (years) }\end{array}$} & $\begin{array}{c}\text { Dura- } \\
\text { tion } \\
\text { (years) }\end{array}$ & $\begin{array}{c}500 \\
\mathrm{~Hz}\end{array}$ & $\begin{array}{c}1000 \\
\mathrm{~Hz}\end{array}$ & $\begin{array}{c}20000 \\
\mathrm{~Hz}\end{array}$ & $\begin{array}{c}3000 \\
\mathrm{~Hz}\end{array}$ & $\begin{array}{c}4000 \\
\mathrm{~Hz}\end{array}$ & $\begin{array}{c}6000 \\
\mathrm{~Hz}\end{array}$ \\
\hline 30 & 10 & 0.5 & 0.6 & 2.0 & 6.4 & 9.2 & 6.7 \\
\hline 40 & 20 & 1.7 & 1.9 & 5.3 & 11.2 & 15.4 & 13.3 \\
\hline 50 & 30 & 3.6 & 4.1 & 9.5 & 17.7 & 24.0 & 22.9 \\
\hline 55 & 35 & 4.8 & 5.5 & 12.1 & 21.6 & 29.3 & 29.0 \\
\hline 60 & 40 & 6.2 & 7.1 & 14.9 & 26.1 & 35.3 & 35.9 \\
\hline
\end{tabular}




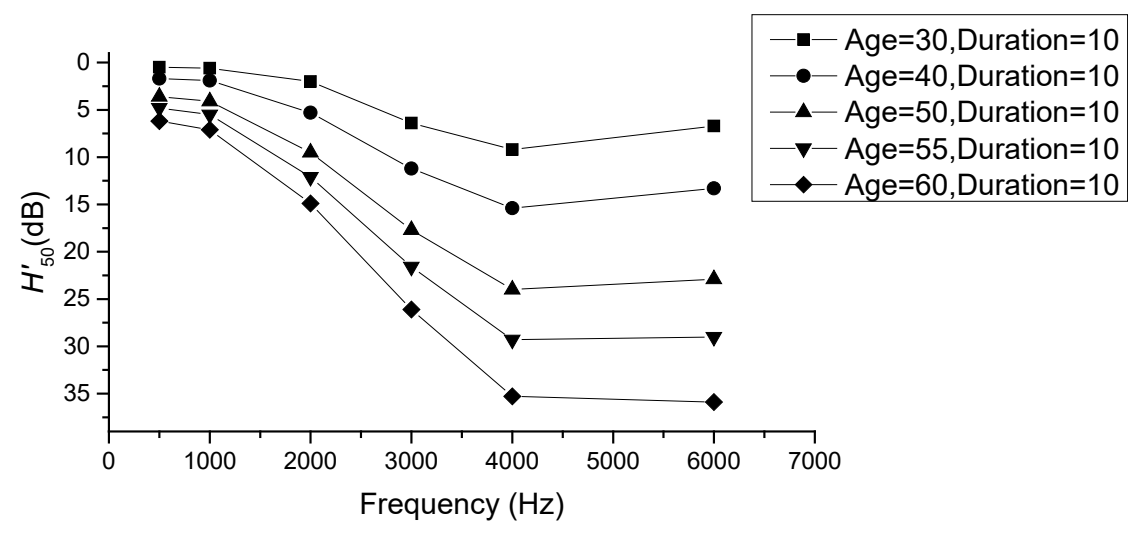

Fig.3. Predicted results of H' 50 of each frequency for the male workers of the workshop.

Table 6. Predicted results of N50 of each frequency for the male workers of the workshop

\begin{tabular}{|c|l|c|c|c|c|c|c|}
\hline \multirow{2}{*}{$\begin{array}{c}\text { Age } \\
\text { (years) }\end{array}$} & $\begin{array}{l}\text { Dura- } \\
\text { tion } \\
\text { (years) }\end{array}$ & \multicolumn{6}{|c|}{$N_{50}$ (not be modified $)(\mathrm{dB})$} \\
\cline { 3 - 8 } & $\mathrm{Hz}$ & $\begin{array}{c}1000 \\
\mathrm{~Hz}\end{array}$ & $\begin{array}{c}2000 \\
\mathrm{~Hz}\end{array}$ & $\begin{array}{c}3000 \\
\mathrm{~Hz}\end{array}$ & $\begin{array}{c}4000 \\
\mathrm{~Hz}\end{array}$ & $\begin{array}{c}6000 \\
\mathrm{~Hz}\end{array}$ \\
\hline 30 & 10 & 0 & 0 & 1.0 & 4.8 & 7.1 & 4.2 \\
\hline 40 & 20 & 0 & 0 & 1.9 & 5.9 & 8.1 & 4.9 \\
\hline 50 & 30 & 0 & 0 & 2.5 & 6.5 & 8.8 & 5.3 \\
\hline 55 & 35 & 0 & 0 & 2.7 & 6.8 & 9.0 & 5.5 \\
\hline 60 & 40 & 0 & 0 & 2.9 & 7.0 & 9.2 & 5.6 \\
\hline
\end{tabular}

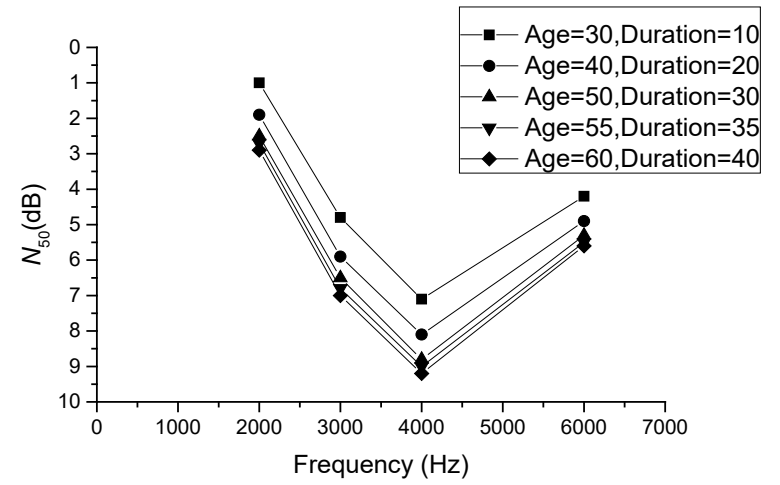

Fig.4. Predicted results of N50 of each frequency for the male workers of the workshop.

\section{Conclusions and Discussions}

It should be noted that all sound pressure levels do not consider the effect of hearing protectors which would reduce effective exposure levels. Hearing protectors could be worn to reduce the effective exposure levels to protect the hearing of workers exposed to industrial noise.
Database $A$ is chosen in this application example analysis. If database B is needed, only Sweden, Norway and the United States data are available, this may be lack of convincing when they are used to assess the risk of hearing loss of Chinese population. In further research, a hearing threshold level database of Chinese population could be compiled following proper principles reference to the levels of the three countries of database B in ISO 1999:2013(E).

Besides, it is emphasized that for practical situations the accuracy of the prediction of the hearing threshold level of a noise-exposed population will largely be a function of the accuracy of the selected database for HTLA, so the results are only estimated values in statistics. This ISO model is based on statistical data and therefore cannot be applied to the prediction or assessment of the hearing loss of individual persons except in terms of statistical probabilities.

The frequencies and fences are chosen based on the HSTS defined in the "Hearing Protection Specification for Employee in Industrial Enterprises" and the precondition and definition of occupational noise deafness level according to the GBZ 49-2014. The choice of frequencies and fences, though determined primarily by medico-legal considerations, can also be influenced by economic and ethical considerations.

This method to assess the noise occupational exposure risk could be used to quantitatively estimate the risk of hearing loss due to noise, guide the enterprises to take effective risk management measures to protect the workers' health according to the different risk levels estimated, such as making a hearing conservation pro- 
gram and implementing the occupational exposure evaluation, engineering control, organization and management, selection and use of hearing protectors, occupational health surveillance, warning for occupational hazards, training and records management, effectiveness evaluation of hearing conservation program, etc.

\section{Acknowledgements}

This study was supported by Municipal Key Science and Technology Support Project of Tianjin (No. 13ZCZDSY02300).

\section{References}

[1] ISO 1990:1975 (E) Acoustics - Assessment of occupational noise exposure for hearing conservation purposes

[2] ISO 1999:1990(E) Acoustics- Determination of occupational noise exposure and estimation of noise-induced hearing impairment

[3] ISO 1999:2013(E) Acoustics - Estimation of noise-induced hearing loss

[4] GBZ 49-2014 Diagnosis of occupational noise-induced deafness

[5] Robert I Davis, Wei Qiu, Nicholas J Heyer. The use of the kurtosis metric in the evaluation of occupational hearing loss in workers in China: Implications for hearing risk assessment. Noise \&Health, 2012, 14(61) : 330 34 